\title{
ЭВОЛЮЦИЯ ЧЕЛОВЕКОПОДОБНЫХ РОБОТИЗИРОВАННЫХ СИСТЕМ: ВЗГЛЯД ИЗ ПРОШЛОГО В БУДУЩЕЕ
}

\author{
Путников Д., Голубков П.С., Егоров В.Б. \\ Одесская национальная академия пищевых технологий, Одесса, Украина \\ ORCID: ${ }^{1} 0000-0003-2577-8858 ;{ }^{3} 0000-0003-4699-834 X$ \\ E-mail: ${ }^{1}$ ulkiorrrra@gmail.com, ${ }^{2}$ falloutfor@gmail.com
}

Copyright (C) 2018 by author and the journal "Automation technologies and business - processes. This work is licensed under the Creative Commons Attribution International License (CC BY). http://creativecommons.org/licanses/by/4.0

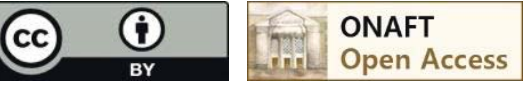

DOI: $10.15673 /$ atbp.v10i1.874

Аннотация: C давних лет писатели фантасты в своих произведениях создавали многоцелевые машины, выполняющие задачи вместе с людьми, либо за них. Позднее чешским писателем Карелом Чапеком и его братом Йозефом было придумано слово робот и впервые использовано в пьесе Чапека «Р. У. Р.». Одним из первых, чертёж человекоподобного робота был сделан Леонардо да Винчи около 1495 года. А в 1738 году франиузский механик и изобретатель Жак де Вокансон создал первое работающее человекоподобное устройство (андроид), которое играло на флейте. В конце 20 столетия, ученые начали вести разработки двуногих человекоподобных роботов, которые смогли бы выполнять за человека опасную и монотонную работу. Первого такого робота представила японская компания. Он был очень большим и на один шаг ему требовалось 5 секунд. Спустя 36 лет в 2013 году ученые создали робота Аsiто, который может стать отличным домашним помощчником, а по количеству функций является одним из самых развитых двуногих роботов в мире на сегодняшний день. Разработки таких роботов ведутся учеными и по сей день.

Abstract: From ancient times, science fiction writers in their works created multi-purpose machines those perform tasks with or for people. Later, by the Czech writer Karel Čapek and his brother Joseph the word robot was coined and first used in Čapek's play “R. W.R.". One of the first, a drawing of a humanoid robot was made by Leonardo da Vinci around 1495 . And in 1738, the French mechanic and inventor Jacques de Vaucanson created the first working humanoid device (android) that played the flute. At the end of the 20th century, scientists began to develop two-legged humanoid robots that could perform dangerous and monotonous work for humans. The first such robot was presented by a Japanese company. He was very big and to do one step he spent 5 seconds. After 36 years in 2013, scientists created the Asimo robot, which can become an excellent home assistant, and in terms of the number of functions, it is one of the most developed bipedal robots in the world today. The development of such robots are conducted by scientists to this day.

Ключевые слова: экзоскелет, андроид, Honda, Boston Dynamycs, HACA, Asimo, робот, Atlas, DURUS, FEDOR.

Key words: exoskeleton, android, Honda, Boston Dynamycs,NASA, Asimo, robot, Atlas, DURUS, FEDOR.

С давних лет писатели фантасты в своих произведениях создавали многоцелевые машины, выполняющие задачи вместе с людьми, либо за них. Искусственные создания, созданные людьми впервые упоминались в древнегреческих мифах. О первом практическом применении прообразов современных роботов - механических людей с автоматическим управлением относятся к эллинистической эпохе. Впервые слово робот было придумано чешским писателем Карелом Чапеком и его братом Йозефом и впервые использовано в пьесе Чапека «Р. У. Р.» («Россумские универсальные роботы», 1920). В ранних русских переводах использовалось слово «работарь». При этом прообразами роботов были также механические фигуры, созданные арабским учёным и изобретателем Аль-Джазари (1136-1206). К примеру, он создал лодку с четырьмя механическими музыкантами, которые играли на бубнах, арфе и флейте. Одним из первых, чертёж человекоподобного робота был сделан Леонардо да Винчи около 1495 года. Записи Леонардо, найденные в 1950-х, содержали детальные чертежи механического рыцаря, способного сидеть, раздвигать руки, двигать головой и открывать забрало. Дизайн, скорее всего, основан на анатомических исследованиях, записанных в Витрувианском человеке. Неизвестно, пытался ли Леонардо построить робота. В XVI-XVIII веках в Западной Европе получило значительное распространение конструирование автоматонов - заводных механизмов, внешне напоминающих человека или животных и способных иногда выполнять достаточно сложные движения. 
Французский механик и изобретатель Жак де Вокансон создал в 1738 году первое работающее человекоподобное устройство (андроид), которое играло на флейте. Позже в литературе в научно-фантастических произведениях, начали фигурировать Экзоскелеты. Чаще всего они упоминаются, как военная техника - в виде силовой брони или боевого скафандра. Впервые, концепция брони с экзоскелетом была изложена в романе «Том Свифт и его реактивный морпех» (Tom Swift and His Jet Marine) из многоавторской серии «Том Свифт», опубликованном в 1954 году. На текущий момент экзоскелеты, которые были придуманы писателями фантастами более чем 100 лет назад, уже начали входить в нашу повседневную жизнь. Множество лабораторий по всему миру изучают и разрабатывают алгоритмы для многоцелевых устройств, облегчающих людям жизнь. Среди этих аппаратов имеются различного типа экзоскелеты. Экзоскеле́т - устройство, предназначенное для восполнения утраченных функций, увеличения силы мышц человека и расширения амплитуды движений за счёт внешнего каркаса и приводящих частей. Экзоскелет повторяет биомеханику человека для пропорционального увеличения усилий при движениях. Экзоскелет, оснащенный системой, позволяющей ему двигаться самостоятельно является роботом. Первый робот в мире был создан японскими учеными в 1970-х, который назывался WABOT-1. Он мог ходить, общаться и поднимать предметы. Впрочем, его ходьбу нельзя было назвать свободной: дистанция была ограничена кабелем питания.

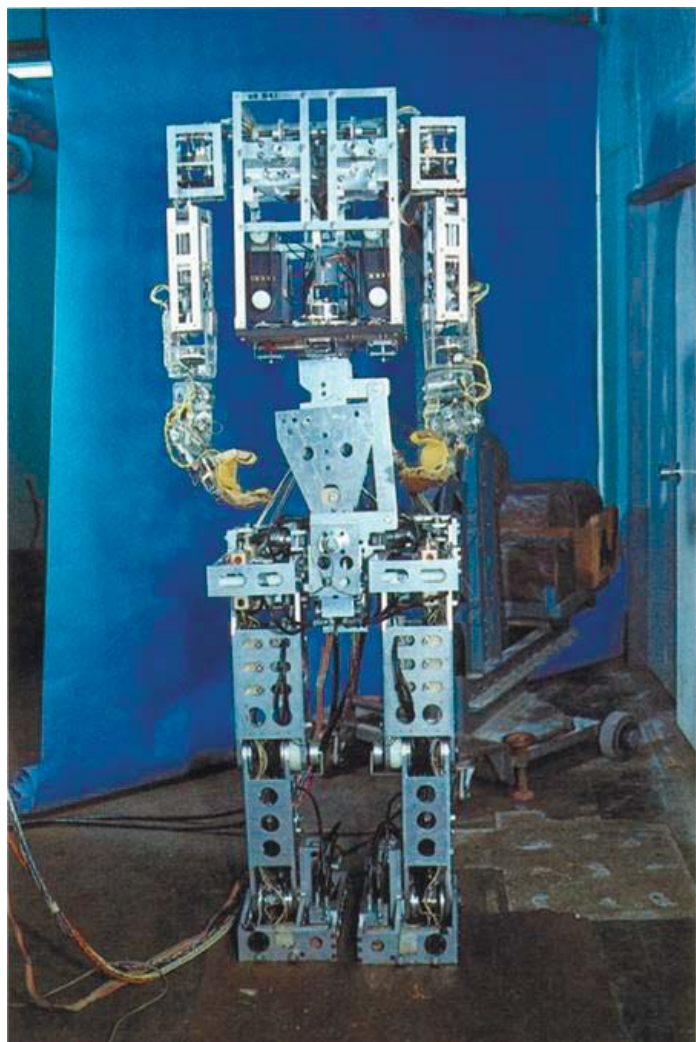

Рис. 1 - Первый японский робот WABOT-1

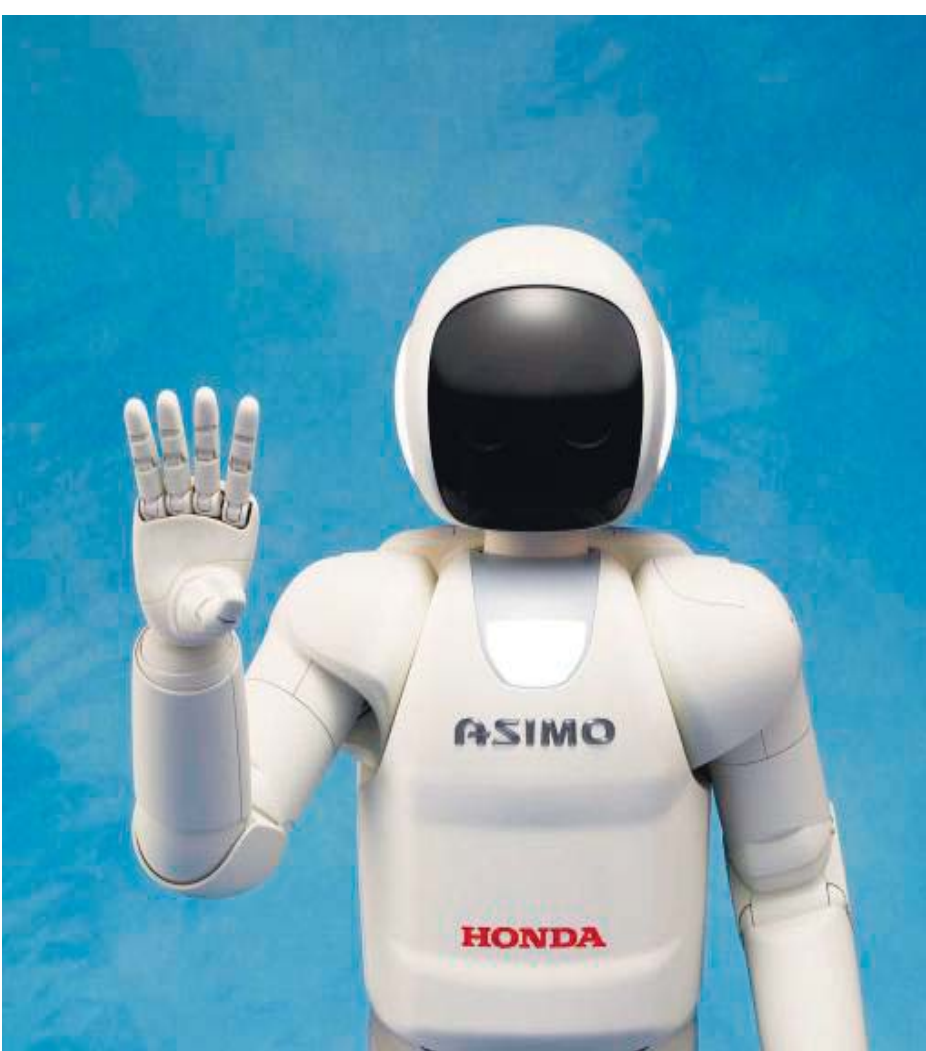

Рис. 2 - Робот Аsimo последней версии

В середине 1980-х годов японские ученые сильно озадачились созданием робота, который мог бы ходить свободно. Первая из таких машин была представлена миру в 1986 году в Японии, и на один шаг ей требовалось 5 секунд. Впрочем, с человеком этот робот имел сходство более чем условное: его «тело» состояло практически из одних «ног». Около 15 лет потребовалось японцам на то, чтобы создать Аsimo - андроида, который свободно ходил, мог открывать двери, вступать во взаимодействие с людьми и выполнять бытовые задачи.

Стремительное развитие японских разработок в области антропоморфных роботов побудило многих ученых по всему миру к исследованиям в данной сфере. Сейчас в США многие университеты конструируют двуногих шагающих роботов, пишут для них алгоритмы и совершенствуют их. Таким примером может служить компания Воston Dynamics, в состав которой входят инженеры конструкторы из Массачусетского технологического университета. Компания разрабатывает роботов в основном для военных целей. Своего антропоморфного робота создатели назвали Atlas. Он является настояним силачем среди себе подобных , т.к. может поднимать груз, весом до 70 кг. Кроме того, робот умент ходить по любой поверхности, бегать, передвигаться на корточках, подниматься по лестнице, а обладая сложной системой датчиков, робот способен сохранять равновесие на одной ноге, даже если что-то попытается сбить его. Основное предназначение этого робота в идеальном будущем - это полная замена спасателей и саперов. В планах создателей научить его разгребать завалы, обезвреживать бомбы и работать там, где не выжить человеку. На данный момент Atlas является одним из самых развитых человекоподобных роботов в мире.

В Космическом центре НАСА, вдохновившись персонажами «Звездных войн», разработали робота-андроида Валькирию (Valkyrie). Валькирия передвигается на двух ногах. Робот имеет подвижные руки и хорошо захватывает 
предметы ладонью. На данный момент он хорошо преодолевает поверхность с неровностями, не спотыкаясь и не падая. Достичь этого удалось, снабдив робота системой, похожей на ту, что используется в машинах с автопилотом. Система вычисляет расстояние до объектов, посылая сигнал и замеряя скорость ответа, потом определяет подходящие участки, чтобы сделать шаг, и только после этого перемещает корпус робота. У робота нет «ушей», и он не может говорить. В то же время андроид оснащен двумя стереоскопическими камерами - «глазами», камерами на животе и сложным набором датчиков, реагирующих на прикасание и давление. Разработки продолжаются. Ожидается, что в ближайшие несколько лет у робота появятся дополнительные возможности.

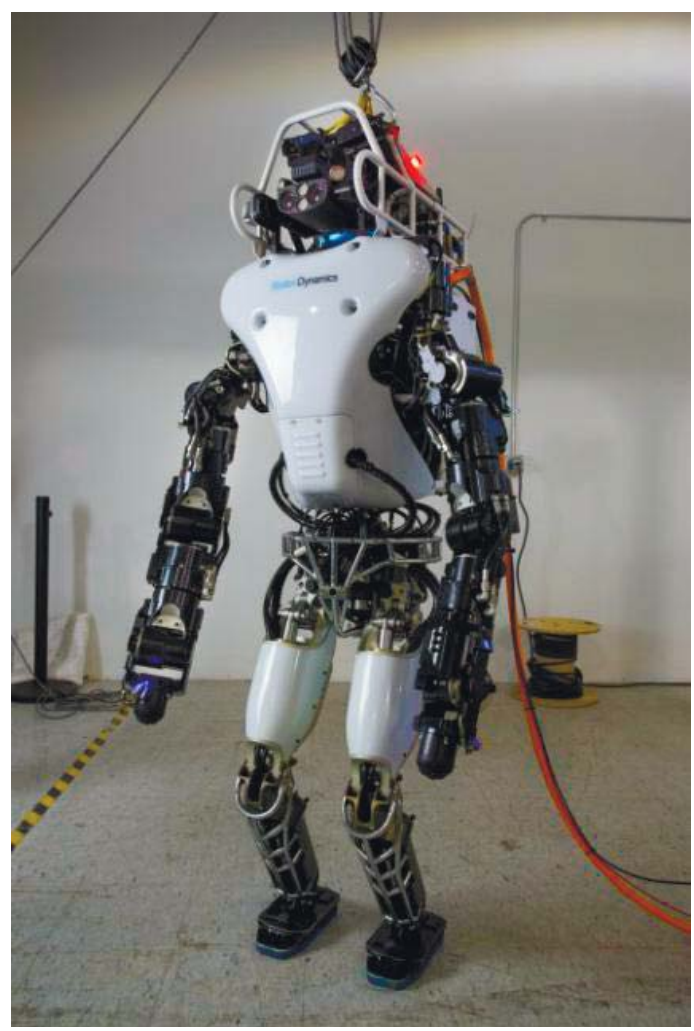

Рис. 3 - Робот Atlas

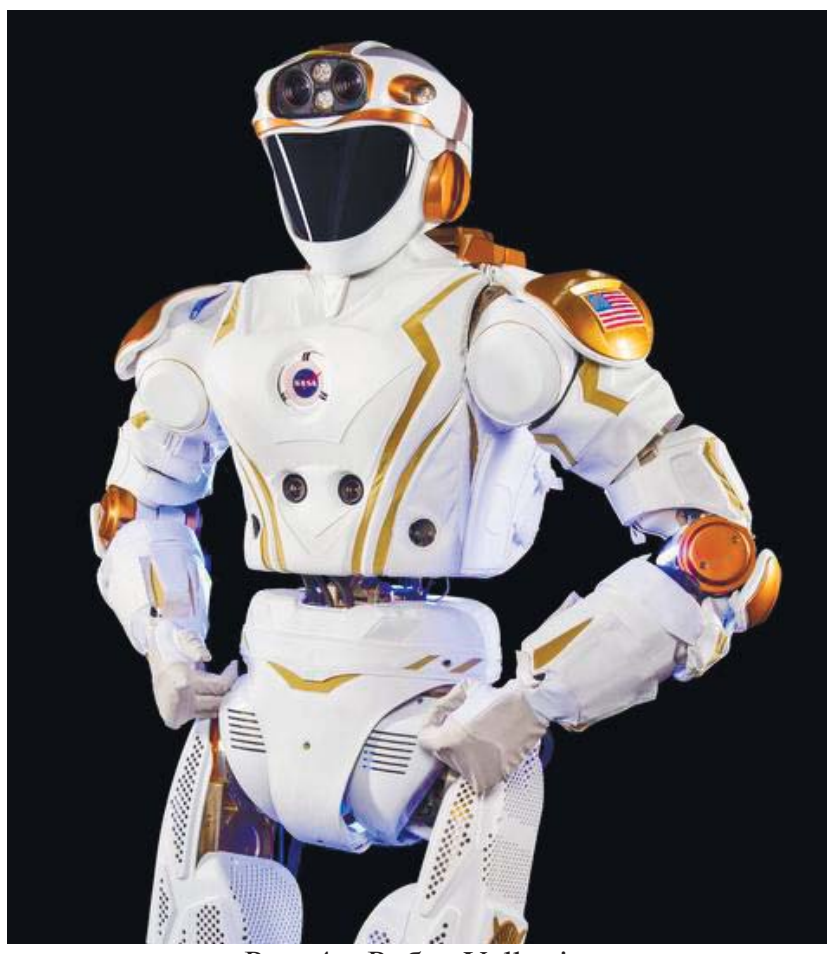

Рис. 4 - Робот Valkyrie

Вся масса датчиков, сервоприводов, двигателей и сопутствующей электроники, которые позволяют гуманоидным роботам ходить на двух ногах, требует достаточно большого количества энергии из аккумуляторных батарей. И все это пока еще делает реальное использование таких роботов не очень подходящим с практической точки зрения. Однако, такая ситуация будет длиться не очень долго, и первой "ласточкой" является робот DURUS, разработанный и созданный специалистами Технологического университета Джорджии. Для передвижения на двух ногах этому роботу требуется гораздо меньше энергии, нежели чем другим из его ближайших "собратьев". Пока еще робот DURUS не столь устойчив при ходьбе, как взрослый человек, его можно сравнить с ребенком, который начал ходить не так давно, но держится на ногах уже вполне устойчиво. Но в отличие от того же робота ATLAS, которому требуется "горбиться" при ходьбе на его плоских стопах, новый робот весьма удачно копирует походку человека, приземляясь при каждом шаге на пятку и отталкиваясь носком. И именно поэтому походка робота DURUS кажется более естественной. Для того, чтобы обеспечить возможность удержания равновесия при ходьбе, в системе управления робота DURUS работает весьма и весьма сложное программное обеспечение. Система управления содержит в своем составе множество регуляторов с обратными связями, позволяют изменять положение верхней части робота, переносить вес с одной ноги на другу и сделать следующий шаг. В ногах робота DURUS использован целый ряд уникальных решений и компонентов, включая мощные пружины, которые накапливают и высвобождают энергию при каждом шаге в момент, когда нога робота входит в контакт с поверхностью.

Пока еще робот DURUS не может быть использован ни в гражданской, ни в военной области, для этого разработчикам предстоит еще сделать множество модернизаций и изменений его конструкции и программного обеспечения.

В России разработкой антропоморфных роботов занимаются МГУ им. Ломоносова, МГТУ им. Баумана, НПО «Андроидная техника». Из последних разработок стоит отметить антропоморфного робота-космонавта SAR-400, которого создали в НПО «Андроидная техника» по заказу Роскосмоса. Вес робота 144 килограмма, он способен выполнять операции с объектами весом до 10 кг. Проведение космических эксперимента с yчастием SAR-400 планируется в 2014 году. 
http://www.atbp.onaft.edu.ua/

Основное отличие российской модели от зарубежных разработок заключается в том, что робот способен передавать человеку-оператору вместе со звуком и картинкой весь спектр ощущений, включая тактильные. Также специалисты говорят о том, что в России существует тенденция «старения общества», которая в скором времени может привести к снижению количества рабочих в промышленности. Поэтому так важны модернизация и автоматизация производства. Еще одна известная разработка российских инженеров, известная во всем мире - робот Федор. Один из самых известных проектов Фонда перспективных исследований. Он был создан в сотрудничестве с НПО «Андроидная техника» по заказу МЧС России. Планируется, что этот робот станет серийным и освоит самые различные отрасли: сможет вытаскивать людей из-под обломков зданий и даже полетит в космос. Работа над ним началась в 2014 году, а широкой общественности он был представлен во второй половине 2016 года. Пока это, скорее, прототип будущего робота - он будет улучшен (в частности, у него появится способность к самообучению) и станет производиться серийно. Сейчас Федор отвечает всем требованиям из технического задания МЧС - там было указано, например, умение открывать дверь ключом или использовать огнетушитель. Дальнейшее развитие робота будет зависеть в том числе и от заказчиков, которых заинтересует данная технология.

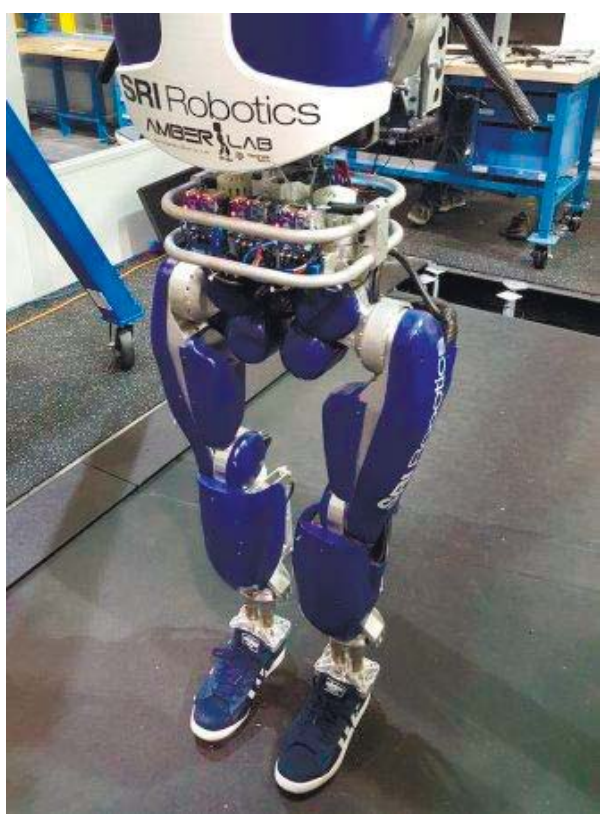

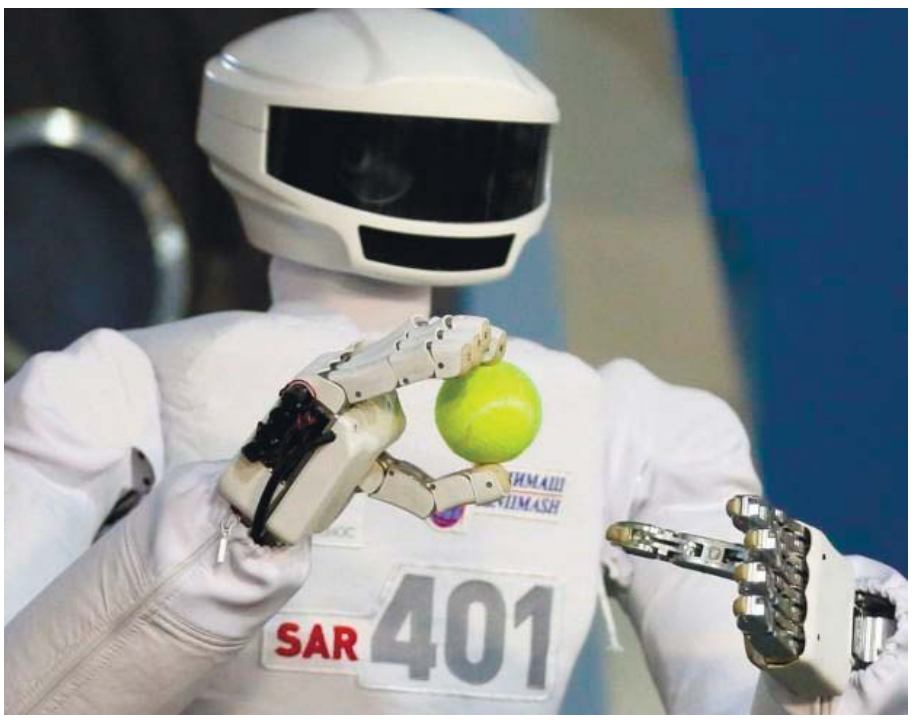

Рис. 6 - Робот SAR-401 (обновлення версия модели SAR400)

Рис. 5 - Робот DURUS

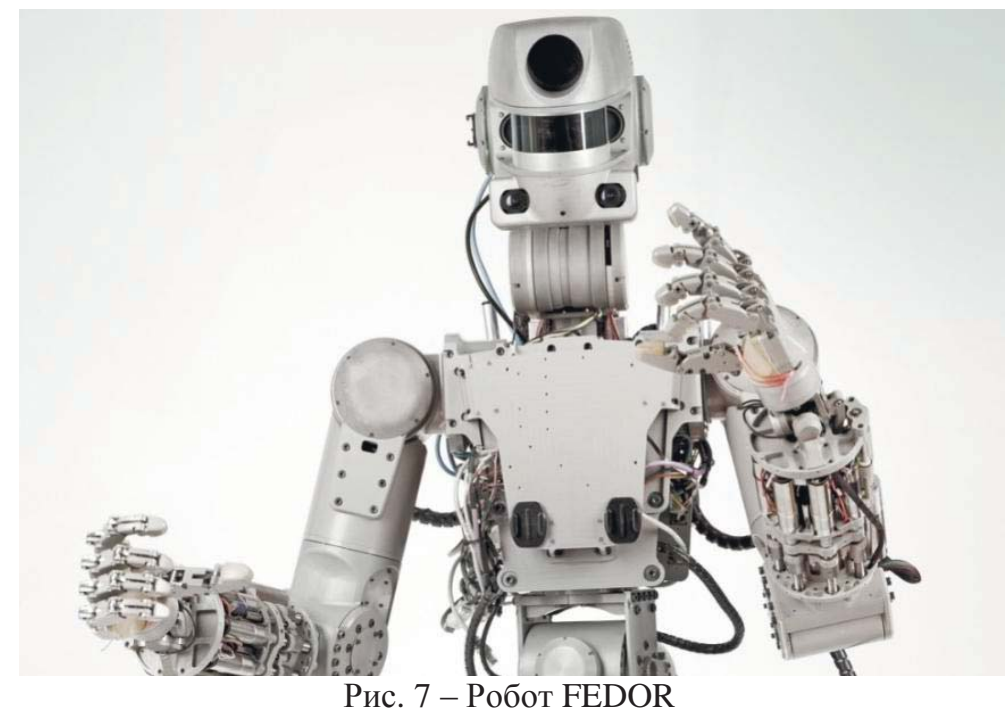

И это далеко не все современные разработки. Сейчас, развитие таких роботов происходит очень высокими темпами, и это очевидно, ведь такие роботы смогут выполнять самые разнообразные задачи, как на Земле, начиная от бытовых задач, заканчивая проведением спасательных операций, так и за ее пределами. По прогнозам ученых, а также лидеров рынка робототехники будущее человекоподобных роботов многообещающее. Когда будут решены все 
основные проблемы и в результате лабораторных испытаний станет очевидно, что функционирование робота не способно нанести ущерб жизни человека, такие роботы будут производиться в серийных масштабах. Некоторые будут предназначены для работы на производстве и смогут заменить людей, а некоторые будут запрограммированы для помощи людям при выполнении бытовых задач.

Вывод: Человекоподобные роботы это относительно молодое и перспективное направление, в котором уже проделано немало работы. Интерес к ним со стороны ученых и организаций очевиден - робот способен работать в любой среде и выполнять любые задачи. Пока, что роботы не способны осуществить тотальное наступление и заменить человека уже сегодня, но уже в обозримом будущем они придут на помощь людям. А люди в свою очередь будут освобождены от тяжелой монотонной работы и смогут выполнять более творческую и интересную работу.

\section{Список использованных источников}

[1] “DURUS -," DURUS - , » DailyTechInfo - , .[Online]. Available: https://www.dailytechinfo.org/robots/8361-durusnovyy-gumanoidnyy-robot-stil-hodby-kotorogo-maksimalno-priblizhen-k-chelovecheskomu.html. [Accessed: 28Sep-2018];

[2] B. Huang, J. Zhao, and L. Sun, "Straight Walking and Stair Climbing Gait of Quadruped Robot Based on Static Balance," Robot, vol. 32, no. 2, pp. 226-232, 2010;

[3] J.-D. Hu and G.-D. Liu, "Whole-body online modification of biped robot walking pattern," Journal of Computer Applications, vol. 31, no. 1, pp. 286-288, 2011;

[4] N. Takase, J. Botzheim, and N. Kubota, "Robot Edutainment on Walking Motion of Multi-legged Robot," 2013 Second International Conference on Robot, Vision and Signal Processing, 2013;

[5] T. Yanase and H. Ib, "Evolutionary Multi-Objective Optimization for Biped Walking of Humanoid Robot," Climbing and Walking Robots, Jan. 2010.

\section{References}

[1] “DURUS - ," DURUS - , » DailyTechInfo - , .[Online]. Available: https://www.dailytechinfo.org/robots/8361-durusnovyy-gumanoidnyy-robot-stil-hodby-kotorogo-maksimalno-priblizhen-k-chelovecheskomu.html. [Accessed: 28Sep-2018];

[2] B. Huang, J. Zhao, and L. Sun, "Straight Walking and Stair Climbing Gait of Quadruped Robot Based on Static Balance," Robot, vol. 32, no. 2, pp. 226-232, 2010;

[3] J.-D. Hu and G.-D. Liu, "Whole-body online modification of biped robot walking pattern," Journal of Computer Applications, vol. 31, no. 1, pp. 286-288, 2011;

[4] N. Takase, J. Botzheim, and N. Kubota, "Robot Edutainment on Walking Motion of Multi-legged Robot," 2013 Second International Conference on Robot, Vision and Signal Processing, 2013;

[5] T. Yanase and H. Ib, "Evolutionary Multi-Objective Optimization for Biped Walking of Humanoid Robot," Climbing and Walking Robots, Jan. 2010. 